\title{
Thymol and Piperine-Loaded Poly(D,L-lactic-co-glycolic acid) Nanoparticles Modulate Inflammatory Mediators and Apoptosis in Murine Macrophages
}

\section{(ㄷ)(1) (우 $\Theta$}

\author{
Authors \\ Jean Paul Dzoyem¹, 2, 3, Nathalie Boulens², 3, Eric Allémann², 3, Florence Delie², 3
}

\section{Affiliations}

1 Department of Biochemistry, Faculty of Science, University of Dschang, Dschang, Cameroon

2 School of Pharmaceutical Sciences, University of Geneva, Geneva, Switzerland

3 Institute of Pharmaceutical Sciences of Western Switzerland, University of Geneva, Geneva, Switzerland

\section{Key words}

thymol, piperine, nanoparticles, anti-inflammatory activity, cytokines, apoptosis

received $\quad 02.03 .2021$

revised 08.06 .2021

accepted 21.06.2021

Bibliography

Planta Med Int Open 2021; 8: e122-e130

DOI 10.1055/a-1543-1190

ISSN 2509-9264

(C) 2021. The Author(s).

This is an open access article published by Thieme under the terms of the Creative Commons Attribution-NonDerivative-NonCommercial-License, permitting copying and reproduction so long as the original work is given appropriate credit. Contents may not be used for commercial purposes, or adapted, remixed, transformed or built upon. (https://creativecommons. org/licenses/by-nc-nd/4.0/).

Georg Thieme Verlag, Rüdigerstraße 14,

70469 Stuttgart, Germany

\section{Correspondence}

Florence Delie

Institute of Pharmaceutical Sciences of Western Switzerland,

University of Geneva

Rue Michel-Servet 1

1211 Geneva

Switzerland

Tel.: +412237 96573, Fax: + 41223796570

Florence.Delie@unige.ch
Jean Paul Dzoyem

Department of Biochemistry, Faculty of Science, University

of Dschang

P. O. Box 67, Dschang

Cameroon

Tel.:+ 237699245686

jpdzoyem@yahoo.fr

( Supplementary Material is available under

https://doi.org/10.1055/a-1543-1190

\section{ABSTRACT}

This study aimed at preparing and characterizing thymol, eugenol, and piperine-loaded poly(D,L-lactic-co-glycolic acid) nanoparticles and evaluating the effect on inflammatory mediators secretion and apoptosis in Raw 264.7 macrophage cells. Nanoparticles were produced by the solvent evaporation technique. Dynamic light scattering and scanning electron microscopy were used to study the physicochemical characteristics. Raw 264.7 macrophage cells were used as a model for in vitro assays. The 2-(4-iodophenyl)-3-(4-nitrophenyl)-5-(2,4-disulfophenyl)-2Htetrazolium assay was used to determine the cytotoxicity of the formulated nanoparticles. An annexin $\mathrm{V}$ apoptosis detection kit was used to assess apoptosis. Nitric oxide production was determined using the Griess reagent, and the inflammatory mediators level was evaluated with Th1/Th2 cytokine and fluorometric cyclooxygenase kits. The loaded nanoparticles showed a particle size around $190 \mathrm{~nm}$ with a low polydispersity between 0.069 and 0.104 and a zeta potential between-1.2 and $-9.5 \mathrm{mV}$. Reduced cytotoxicity of nanoparticles compared to free molecules against Raw 264.7 macrophage cells was observed and seemed to occur through a mechanism associated with apoptosis. A decrease in cyclooxygenase enzyme activity with an increasing concentration was observed. Both free molecules and nanoparticles showed their capacity to modulate the inflammatory process mostly by inhibiting the investigated inflammatory cytokines. The data presented in this study indicate that thymol and piperine-loaded poly(D,L-lactic-co-glycolic acid nanoparticles could serve as a novel anti-inflammatory colloidal drug delivery system with reduced toxicity. However, further study should be considered to optimize the formulation's loading capacity and thereby probably enhance their bioactivity in treating inflammatory diseases. 


$\begin{array}{ll}\text { ABBREVIATIONS } \\ \text { COX } & \begin{array}{l}\text { cyclooxygenase } \\ \text { entrapment efficiency }\end{array} \\ \text { EE } & \begin{array}{l}\text { eugenol nanoparticles } \\ \text { Eug-NPs }\end{array} \\ \text { IFN-y } & \text { interferon-gamma } \\ \text { LC } & \text { loading capacity } \\ \text { LPS } & \text { lipopolysaccharide } \\ \text { NO } & \text { nitric oxide } \\ \text { NSAIDs } & \text { nonsteroidal anti-inflammatory drugs } \\ \text { PDI } & \text { polydispersity index } \\ \text { Pip-NPs } & \text { piperine nanoparticles } \\ \text { PLGA } & \text { poly(D,L-lactic-co-glycolic acid) } \\ \text { PVAL } & \text { polyvinyl alcohol } \\ \text { Thy-NPs } & \text { thymol nanoparticles } \\ \text { WST-1 } & \text { 2-(4-iodophenyl)-3-(4-nitrophenyl)-5-(2,4- } \\ & \text { disulfophenyl)-2H-tetrazolium }\end{array}$

\section{Introduction}

Inflammation is closely linked to cancers, and substantial data has shown that over $25 \%$ of all cancer cases are associated with chronic inflammation and other types of unresolved inflammatory processes [1]. However, current inflammation and cancer therapies, especially NSAIDs and chemotherapy, have been associated with various adverse effects. Moreover, in some cases, therapy failure is due to the inefficient delivery of drugs to tumor cells or the inflammation site [2]. Therefore, efficient delivery of agents that can suppress inflammation-promoted tumors has enormous potential. In this regard, natural products are gaining more attention because of their advantages of efficiency, safety, and few side effects [3]. Recently, major research has focused on the biologically active compounds of spices to develop novel potential drugs for several ailments, especially, against chronic diseases [4]. Spices have been extensively used to enhance or improve food flavor; however, several popular herbs and spices are also known to have beneficial effects for human health. These are mostly attributed to bioactive compounds present in their chemical composition [5]. Recently, the biologically active compounds of spices have been investigated for the development of novel potential drugs as medication for several ailments, especially against chronic diseases [4]. Indeed, thymol, eugenol, and piperine were shown to possess a plethora of pharmacological properties including antioxidant, analgesic, antispasmodic, antimicrobial, antiseptic, antitumor, and anti-inflammatory activities [6]. Piperine is an alkaloid present in Piper species. It has many pharmacological effects and several health benefits, especially against chronic diseases, such as anti-inflammatory effects and improvement of hepatic steatosis [7]. Studies in macrophages documented that the molecular mechanisms of the anti-inflammatory effects of eugenol are mediated by the modulation of inflammatory mediators production [8]. The remarkable anti-inflammatory effect of thymol is largely attributed to the inhibition of inflammatory cytokines and chemokines [9]. Despite the excellent therapeutic potential of thymol, eugenol, and piper- ine, their clinical application is still limited due to high volatility and low bioavailability related to poor aqueous solubility upon oral administration. Therefore, there is a need for an effective orally administered drug delivery system of these anti-inflammatory biomolecules [10]. Encapsulation of hydrophobic drugs in biodegradable polymer nanoparticles has been described as a promising approach for delivery with many advantages for bioactive molecules, including improvement of solubility and bioavailability, protection from toxicity, enhancement of pharmacological activity, improvement of stability, sustained delivery, and protection from physical and chemical degradation [11]. Among all the biodegradable polymers used as a drug delivery carrier, PLGA has been explored most for improving the therapeutic effects of hydrophobic drugs. Owing to its biocompatibility, PLGA has been FDA approved for use in humans for specific applications and has been used in clinical trials [12]. PLGA has shown great potential for improving the effectiveness for plant-derived bioactive compound delivery $[10,13]$. Up to now, there are no studies on polymeric encapsulation of thymol, eugenol, and piperine, and their in vitro evaluation as an anti-inflammatory formulation. Therefore, in this study, thymol, eugenol, and piperine were encapsulated with PLGA, and their in vitro modulatory effects on apoptosis and the level of inflammatory mediators were evaluated in Raw 264.7 macrophage cells.

\section{Results}

The diameter of the nanoparticles was between 192 and $187 \mathrm{~nm}$ ( Table 1). Unloaded nanoparticles showed the smallest mean size of $178 \mathrm{~nm}$ with a PDI of 0.064 and zeta potential of $-2.08 \mathrm{mV}$. The surface morphology of nanoparticles observed by scanning electron microscopy indicated a spherical shape with a smooth surface ( $\triangleright$ Fig. 1). Regarding the EE and the loading, Pip-NPs showed the highest values with $57.39 \% \mathrm{EE}$ and an LC of $6.04 \%$, whereas the lowest percentage was obtained with eugenol (EE of $6.94 \%$ and LC of $0.65 \%$ ) ( Table 1 ).

To improve the entrapment rates of thymol and eugenol, the effect of the addition of sodium chloride $(0.05$ and $0.1 \mathrm{M})$ was studied. - Table 2 shows that the addition of $\mathrm{NaCl} 0.05 \mathrm{M}$ to the external phase increases the EE from 13.73 to $32.78 \%$ for Thy-NPs.

The effect of compounds and nanoparticles on cell viability in RAW 264.7 cells was evaluated by the WST-1 assay. The data presented in > Table 3 shows that the RAW 264.7 macrophages viability was slightly affected by thymol, eugenol, and piperine, with $\mathrm{IC}_{50}$ values of $55.02,46.05$, and $9.69 \mu \mathrm{g} / \mathrm{mL}$, respectively. Although encapsulated, thymol showed a slightly toxic effect; the $\mathrm{IC}_{50}$ $(123.68 \mu \mathrm{g} / \mathrm{mL})$ was almost twofold lower compared to free thymol. No cytotoxicity was observed with unloaded nanoparticles, Pip-NPs, and Eug-NPs. Due to the low EE and its low LC, Eug-NPs were not investigated in the subsequent biological assays.

The cellular uptake of PLGA nanoparticles by RAW 264.7 macrophages was evaluated by confocal microscopy. - Figure 2 shows that PLGA nanoparticles were internalized in cells.

Using flow cytometry analysis, the apoptosis-inducing effects of nanoparticles and free compounds were investigated in Raw 264.7 cells. As seen in > Fig. 3, apoptotic and necrotic cell populations increased with nanoparticles or free compound concentration compared with the untreated or unloaded nanoparticle 
- Table 1 Characteristics of thymol-, eugenol-, and piperine-loaded nanoparticles $(n=3)$.

\begin{tabular}{|c|c|c|c|c|c|}
\hline \multirow[t]{2}{*}{ Nanoparticles } & \multicolumn{5}{|c|}{ Characteristics } \\
\hline & Size (nm) & PDI & $\zeta$-potential (mV) & $\begin{array}{l}\text { Entrapment efficiency } \\
(\%)\end{array}$ & Drug loading (\%) \\
\hline Thymol-NPs & $192.21 \pm 2.82$ & 0.09 & -5.39 & $13.73 \pm 3.76$ & $1.51 \pm 0.54$ \\
\hline Eugenol-NPs & $187.15 \pm 1.43$ & 0.07 & -9.52 & $6.94 \pm 2.65$ & $0.65 \pm 0.05$ \\
\hline Piperine-NPs & $186.39 \pm 4.86$ & 0.10 & -1.17 & $57.39 \pm 6.34$ & $6.04 \pm 1.56$ \\
\hline Unloaded-NPs & $178.62 \pm 2.12$ & 0.06 & -2.08 & na & na \\
\hline
\end{tabular}
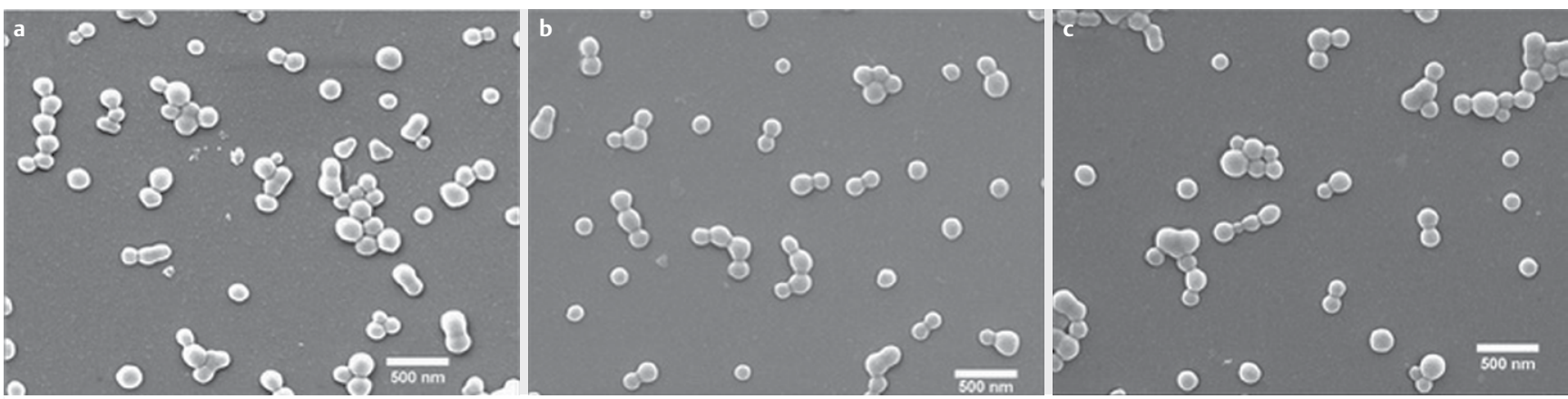

- Fig. 1 Scanning electron microscope micrographs of (a) Thy-NPs, (b) Eug-NPs, and (c) Pip-NPs ( × 30000).

control cells. The percentage of apoptotic cell population increased with concentration except for Pip-NPs, which showed a decrease in percentages from 41.42 to $23.66 \%$ at 5 and $10 \mu \mathrm{g} / \mathrm{mL}$, respectively. At a $5 \mu \mathrm{g} / \mathrm{mL}$ concentration, thymol and Thy-NPs increased the apoptotic cell population from 5.99 to 46.11 and $20.94 \%$, respectively. The dot plots representing the apoptosis-inducing effect of nanoparticles and free drugs on Raw 264.7 cells are shown in Fig. 1S, Supporting Information.

After having established the non-toxicity of formulated nanoparticles towards RAW 264.7 cells, their effect on inflammatory processes was evaluated by quantifying the concentration of cytokines released in their supernatant, namely, NO, TNF- $\alpha$, interferon IFN- $\gamma$, and interleukins (IL-2, IL-4, IL-6, IL-10) in cells under LPS stimulation then compared to that of the free molecule.

The level of NO was measured by the Griess reaction test. - Figure 4 shows that unstimulated macrophages produce a minute amount of NO $(0.07 \mu \mathrm{g} / \mathrm{mL})$, while upon stimulation with LPS, the level NO was $1.54 \mu \mathrm{g} / \mathrm{mL}$.

Unloaded nanoparticles did not show any inhibitory effect. Indomethacin, used as a positive inhibitory control, showed the lowest NO concentration $(0.43 \mu \mathrm{g} / \mathrm{mL})$. At $20 \mu \mathrm{g} / \mathrm{mL}$, the amount of NO released by cells treated with free thymol was $0.72 \mu \mathrm{g} / \mathrm{mL}$, whereas Thy-NPs showed higher values $(1.18 \mu \mathrm{g} / \mathrm{mL})$, with a significant difference at $p<0.0001$. A significant difference was also observed between the inhibitory effect of thymol and Thy-NPs at $5 \mu \mathrm{g} / \mathrm{mL}(\mathrm{p}<0.01), 10 \mu \mathrm{g} / \mathrm{mL}(\mathrm{p}<0.001)$, and $20 \mu \mathrm{g} / \mathrm{mL}(p<$ $0.0001)$. After treatment with free piperine and Pip-NPs $(5 \mu \mathrm{g} / \mathrm{mL})$, the amount of NO released was 0.55 and $0.75 \mu \mathrm{g} / \mathrm{mL}$, respectively. When compared to the LPS-stimulated and non-treated cells, both free piperine and Pip-NPs reduced the production of NO by about two folds. However, the inhibitory effect of Pip-NPs compared to free piperine was not significantly different. According to the cyto- toxicity results, the NO inhibitory effect observed at the concentrations used could not be attributed to a cytotoxic effect ( Table 3).

The BD Cytometric Bead Array Human Th1/Th2 Cytokine Kit II was used to quantitatively measure the secretion of IL-2, IL-4, IL-6, IL-10, TNF- $\alpha$, and IFN- $\gamma$ protein levels in Raw 264.7 macrophage cells stimulated with LPS.

As illustrated by $>$ Fig. 5, PLGA encapsulated and non-encapsulated piperine induced a decrease in cell production of IFN- $\gamma$, TNF$\alpha$, IL-2, and IL- 6 cytokines and no reduction of IL-4 and IL-10 cytokines compared with LPS-stimulated and untreated control cells. Except for TNF- $\alpha$ and IL-6 ( $p<0.0001)$, no other significant difference was observed between the inhibitory effect of piperine and Pip-NPs on the investigated cytokines. An almost similar trend was observed with thymol and Thy-NPs, except for the secretion of IL-2 and IL- 6 for which a significant increase was observed $(p<0.01$ and $p<0.0001$, respectively). Unloaded nanoparticles did not induce any change in cytokine secretion, whereas indomethacin used as a reference anti-inflammatory drug showed a general decrease in all cytokine secretion as expected.

The in vitro COX-1 and COX-2 inhibitory activity of the compounds and nanoparticles was evaluated in Raw 264.7 cells using a fluorescence-based COX assay. The results are summarized in - Fig. 6. Incubation of cells with free molecules and drug-loaded nanoparticles for $24 \mathrm{~h}$ induced the inhibition of COX-1 and COX-2 enzyme activity in a dose-dependent manner. At the highest concentration of the active compound $(5 \mu \mathrm{g} / \mathrm{mL})$, inhibition of COX-1 activity was shown to be $65.25 \mu \mathrm{U} / \mathrm{mg}, 47.17 \mu \mathrm{U} / \mathrm{mg}$ for piperine and Pip-NPs, and 65.77 and $64.25 \mu \mathrm{U} / \mathrm{mg}$ for thymol and Thy-NPs. At the same concentration, COX-2 showed $34.35 \mu \mathrm{U} / \mathrm{mg}, 17.05 \mu \mathrm{U} /$ $\mathrm{mg}$ for piperine and Pip-NPs, and 28.10 and $27.10 \mu \mathrm{U} / \mathrm{mg}$ for thymol and Thy-NPs. There was a significant difference $(p<0.001)$ in 
- Table 2 Effect of $\mathrm{NaCl}$ concentration in the aqueous phase on entrapment efficiency (EE) and drug loading (DL) of Thy-NPs and Eug-NPs ( $\mathrm{n}=3$ ).

\begin{tabular}{|c|c|c|c|c|}
\hline \multirow[t]{3}{*}{ Nanoparticles } & \multicolumn{4}{|c|}{$\mathrm{NaCl}$ concentration } \\
\hline & \multicolumn{2}{|c|}{$50 \mathrm{mM}$} & \multicolumn{2}{|c|}{$100 \mathrm{mM}$} \\
\hline & EE (\%) & $\mathrm{DL}(\%)$ & $\mathrm{EE}(\%)$ & $\mathrm{DL}(\%)$ \\
\hline Thymol-NPs & $32.78 \pm 6.08$ & $3.78 \pm 2.07$ & $3.53 \pm 1.34$ & $0.40 \pm 1.06$ \\
\hline Eugenol-NPs & $6.28 \pm 3.08$ & $0.68 \pm 1.15$ & $1.06 \pm 0.31$ & $0.12 \pm 0.01$ \\
\hline
\end{tabular}
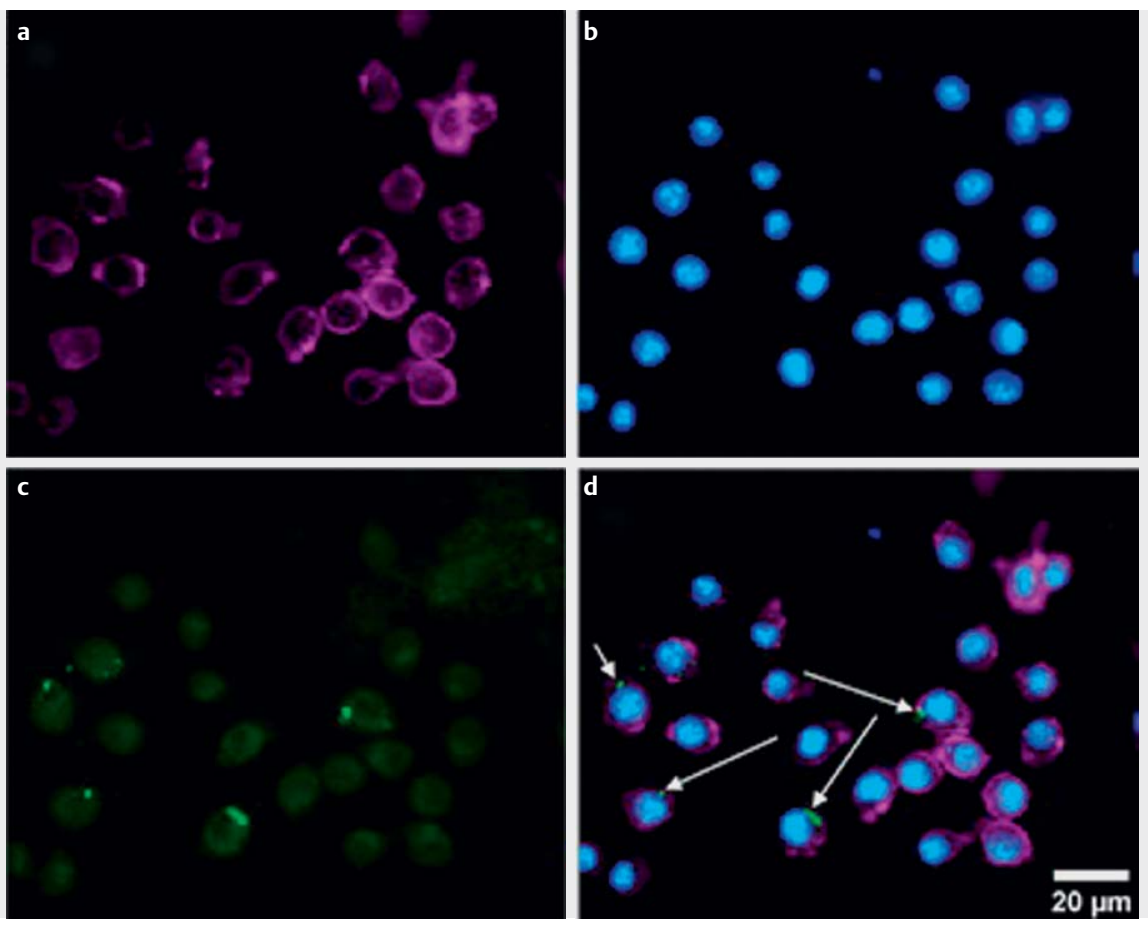

- Fig. 2 Cellular uptake of nanoparticles by Raw 264.7 macrophage cells. a Cell F-actin labeled with phalloidin (pink). b Cell nuclei stained with Hoechst (blue). c Nanoparticles prepared with DiO (green). d Overlay of the three stainings.

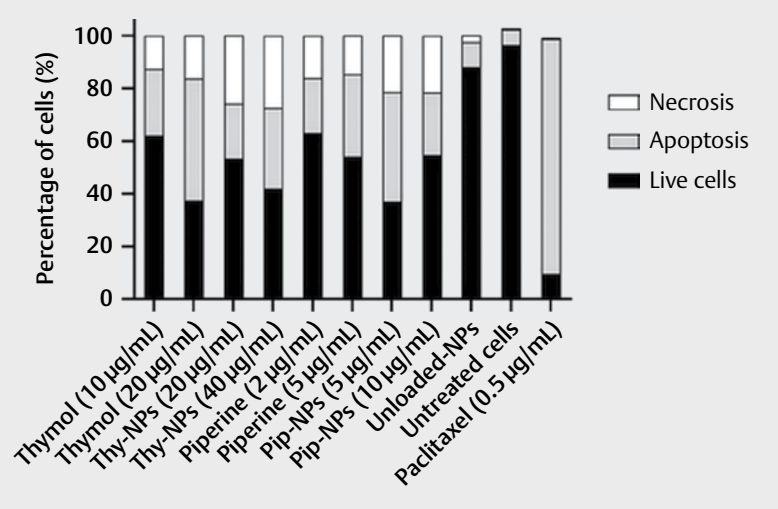

Fig. 3 Histograms representing the apoptosis-inducing effect of nanoparticles and free drugs on Raw 264.7 cells. Cells were treated for $24 \mathrm{~h}$, then annexin V/propidium iodide (PI) staining was performed and analyzed by flow cytometry. Paclitaxel was used as a positive control and untreated cells as a negative control.

This study aimed to formulate and test PLGA nanoparticles loaded with the bioactive plant compounds thymol, eugenol, and piper-
- Table 3 Cytotoxicity of nanoparticles and free compounds on Raw 264.7 macrophage cells $(n=3)$.

\begin{tabular}{|l|l|l|l|}
\hline \multirow{2}{*}{ Compounds } & $\mathbf{I C}_{\mathbf{5 0}}(\boldsymbol{\mu g} / \mathbf{m L})$ & \multicolumn{2}{|c|}{ Increase fold of $\mathbf{I C}_{\mathbf{5 0}}$} \\
\cline { 2 - 4 } & $\begin{array}{l}\text { Free } \\
\text { compound }\end{array}$ & Nanoparticles & \\
\hline Thymol & $55.02 \pm 0.12$ & $123.68 \pm 0.63$ & 2.2 \\
\hline Eugenol & $46.05 \pm 2.53$ & $>200$ & $>4$ \\
\hline Piperine & $9.69 \pm 2.34$ & $>100$ & $>10$ \\
\hline Unloaded-NPs & - & $>200$ & - \\
\hline Paclitaxel & $0.65 \pm 0.02$ & - & - \\
\hline Indomethacin & $>200$ & - & - \\
\hline
\end{tabular}

characteristic of the PLGA nanoparticles was observed, indicating that the compounds were effectively associated with and/or within the PLGA polymeric matrix. The PDI values revealed a homogenous nanoparticle population, which was consistent with the scanning electron microscopy analysis. Their slight water solubility could explain the poor EE and the poor LC of thymol and eugenol. Thymol and eugenol are soluble in water up to 0.9 and $2.4 \mathrm{mg} / \mathrm{mL}$, respectively. These compounds were somehow poorly encapsulated due to the molecules diffusion from the organic dispersed phase 


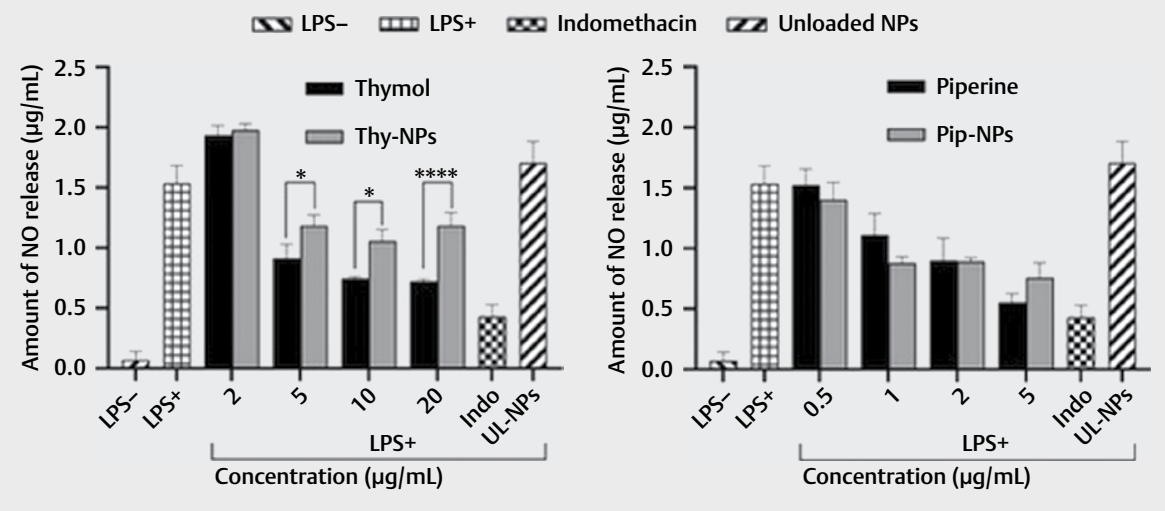

-Fig. 4 Inhibitory effects of nanoparticles and free drugs on Raw 264.7 cells on NO production in LPS-stimulated RAW 264.7 macrophages. Cells were stimulated with $100 \mathrm{ng} / \mathrm{mL}$ of LPS. Indomethacin (Indo) was tested at $5 \mu \mathrm{g} / \mathrm{mL}$. Values are the mean of three independent experiments in triplicate determinations $(n=3) \pm$ standard deviation. Statistical analysis was performed with Dunnett's multiple comparisons test using twoway ANOVA. " $\mathrm{P}<0.05,{ }^{*} \mathrm{p}<0.01,{ }^{* *} \mathrm{*} p<0.001$, and " * * $\mathrm{p}<0.0001$ between free drugs and drug-loaded nanoparticles.

into the continuous external aqueous phase during the evaporation step. In this case, the addition of salt to the aqueous external phase is one approach to improve drug loading into nanoparticles [14]. In our study, the addition of $\mathrm{NaCl} 0.05 \mathrm{M}$ to the external phase led to an increase in EE, which could be attributed to the increased osmotic pressure of the external phase by adding salts [15]. However, increasing salinity to $0.1 \mathrm{M}$ showed no further improvement. Instead, a high salt concentration $(0.1 \mathrm{M})$ caused a lower EE than $0.05 \mathrm{M}$. This finding was previously described in other studies. A decrease in the EE of topotecan-loaded PLGA nanoparticles due to high ionic strength has been observed previously and was attributed to changes in the aqueous solubility of both the drug and the organic solvent [16]. The use of $\mathrm{NaCl}$ has shown its effect on quick polymer precipitation, which leads to a higher EE; however, a high concentration delayed polymer precipitation, which in turn decreases the EE [17].

RAW 264.7 cells are being described as an appropriate model of macrophages. It is a well-established model to evaluate drug candidates anti-inflammatory activity, as they produce inflammatory mediators under stimuli [18]. To observe whether compounds and nanoparticles had any toxic effects on cells and to select suitable concentrations to be used in the subsequent in vitro experiments, we examined the effects of compounds and nanoparticles on cell viability in RAW 264.7 cells. Unlike free thymol, eugenol, and piperine, which showed cytotoxicity, Pip-NPs did not show an obvious cytotoxic effect, which suggests an interesting strategy for use without generating cell damage. From the cytotoxicity data, concentrations of compounds and nanoparticles below the $\mathrm{IC}_{50}$ values were selected for further biological assays.

As macrophages, RAW 264.7 cells can perform pinocytosis and phagocytosis. They were used to study the cellular inflammatory responses to formulated thymol and piperine nanoparticles. Results indicate that our nanoparticle diameters $(<200 \mathrm{~nm}$ ) were adequate for cell phagocytosis. In vitro studies have shown that nanoparticles having less than $200 \mathrm{~nm}$ are efficiently internalized by Raw 264.7 macrophages [19]. It has also been reported that the size and surface chemistry of nanoparticles influence the cellular uptake, and, in particular, PLGA polymer particles have the ability to interact with the cell surface to facilitate the uptake [20].

The contribution of NO to trigger apoptosis in macrophages has been well established [21]. Therefore, we sought to further analyze the apoptosis-inducing effect of nanoparticles compared to free molecules. The induction of apoptosis in activated macrophages has been recognized as a physiological mechanism that reduces inflammatory stress [21,22]. Our results indicate that the slight cytotoxicity of free compounds and nanoparticles against Raw 264.7 macrophages cells might occur through a mechanism associated with apoptosis. Thymol and piperine have been found to alter various cell lines via an apoptotic mechanism [23, 24].

A balance between pro-and anti-inflammatory cytokines is necessary to maintain homeostasis. Our study indicates that piperine and Pip-NPs induce a decrease in proinflammatory cytokines and increase anti-inflammatory cytokines. Thymol and Thy-NPs showed an opposite effect in the secretion of IL-6. This multiple and sometimes opposite effect of thymol and Thy-NPs on investigated cytokine production is interesting, considering the pleiotropic effect of IL-6. Indeed, IL-6 acts as both a proinflammatory and an anti-inflammatory cytokine, regulating not only the immune and inflammatory response, and also affects hematopoiesis [25]. In this study, the general trend of this enzyme activity reduction shows a decrease in the two enzymes activity with increasing concentration, indicating the anti-inflammatory potential of the formulated nanoparticles by regulating COX activity. Overall, both free molecules and nanoparticles showed their capacity to modulate the inflammatory process mostly by inhibiting the investigated inflammatory mediators. However, nanoparticles showed lower inhibitory potency than the free compounds against both isoenzymes, which could be explained by the extended release and action of the encapsulated drug.

NO is an important mediator in the persistence of inflammation that contributes to its pathogenicity. Excessive production of NO by NO synthase has pathological consequences for many organ sys- 

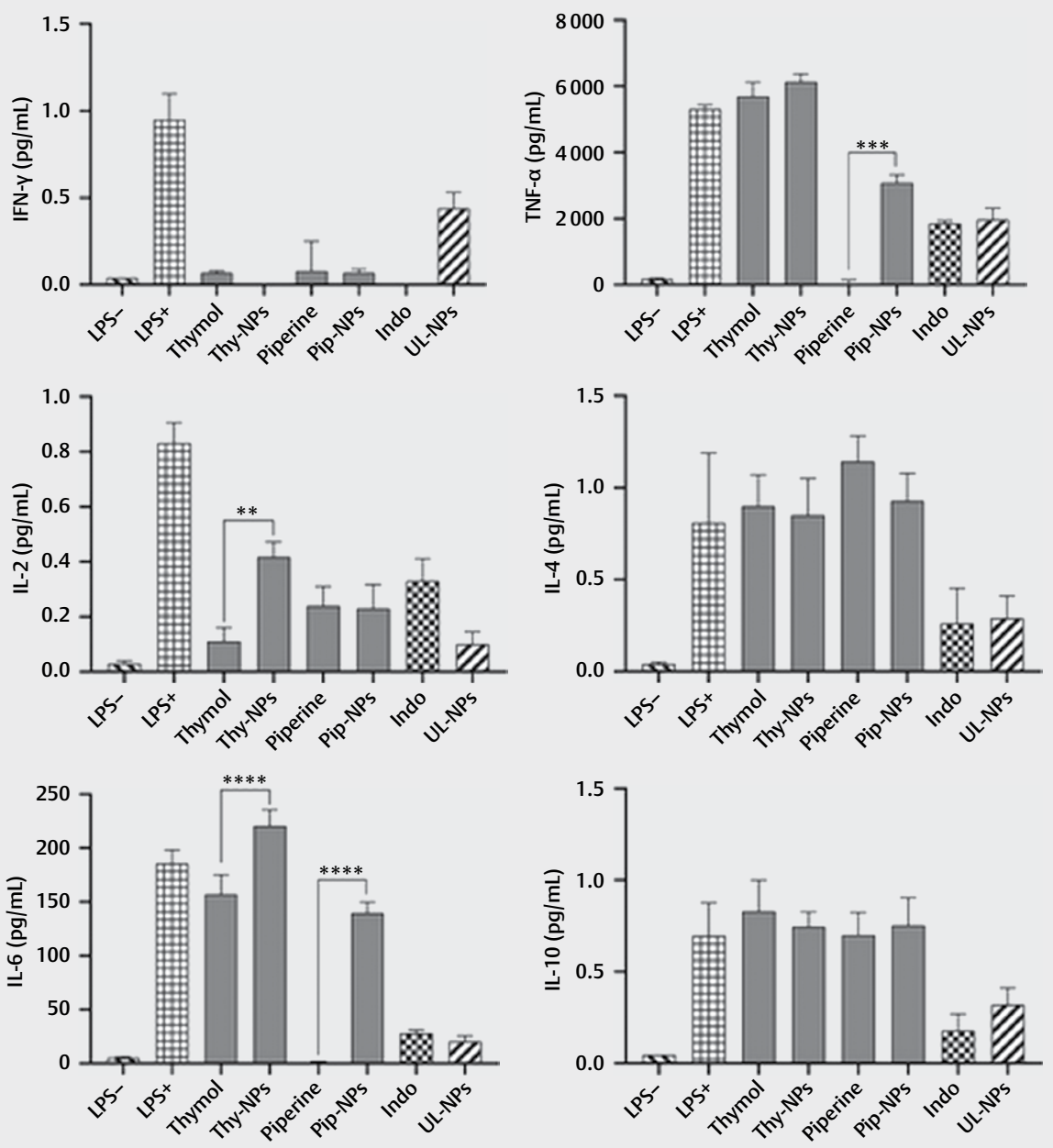

Fig. 5 Effects of nanoparticles and free drugs on inflammatory cytokines production in Raw 264.7 macrophages. Cells were treated for $24 \mathrm{~h}$ with $20 \mathrm{\mu g} / \mathrm{mL}$ of thymol nanoparticles (Thy-NPs) and free thymol or $5 \mu \mathrm{g} / \mathrm{mL}$ of piperine nanoparticles (Pip-NPs) and free piperine, followed by a quantitative determination of cytokine levels. Indomethacin (Indo) was tested at $5 \mu \mathrm{g} / \mathrm{mL}$. Values are the mean of one experiment in triplicate $(n=3) \pm$ standard deviation. Statistical analysis was performed with Dunnett's multiple comparisons test using two-way ANOVA. ${ }^{*} \mathrm{P}<0.05,{ }^{* *} \mathrm{p}<0.01,{ }^{* * *} \mathrm{p}<0.001$, and ${ }^{* * * *} \mathrm{p}<0.0001$ between free drugs and drug-loaded nanoparticles.

tems of the body, leading to tissue damage, the development of inflammation, and inducing cell death [26]. Hence, to control its production is a principal role in an anti-inflammatory investigation. Treatment with thymol and piperine, as well as their nanoparticle formulations, reduced this production in a dose-dependent manner. However, overall, a marked NO inhibitory effect of nanoparticles was observed compared to the free substances in the concentration range investigated.

This study shows the possibility of the delivery of poorly watersoluble thymol and piperine. Moreover, we demonstrate that incorporating thymol and piperine in the PLGA polymer protects from toxicity and maintains their inflammatory modulating properties. Thus, our findings open a path to new forms of administration of bioactive thymol and piperine.

Formulated nanoparticles showed reduced cytotoxicity on RAW 264.7 macrophage cells compared to the free drugs and an antiinflammatory effect by inhibiting cytokines and COX enzyme activity. Based on our findings, it could be concluded that thymol and piperine-loaded PLGA nanoparticles could serve as a novel colloidal drug delivery system to reduce toxicity. Further study should be considered to optimize the formulations loading capacity and thereby probably enhance their bioactivity in the treatment of inflammatory diseases.

\section{Material and Methods}

For all experiments, the concentrations of Thy-NPs and Pip-NPs used are the corresponding amounts of entrapped drug calculated from drug loading. The concentration of unloaded nanoparticles is equivalent to the concentration of loaded nanoparticles providing the highest concentration of drug used.

\section{Natural product compounds and reagents}

Natural products thymol (purity $\geq 98.5 \%$ ), eugenol (purity $99 \%$ ), and piperine (purity $\geq 97 \%$ ), 3,3'-dioctadecyloxacarbocyanine per- 

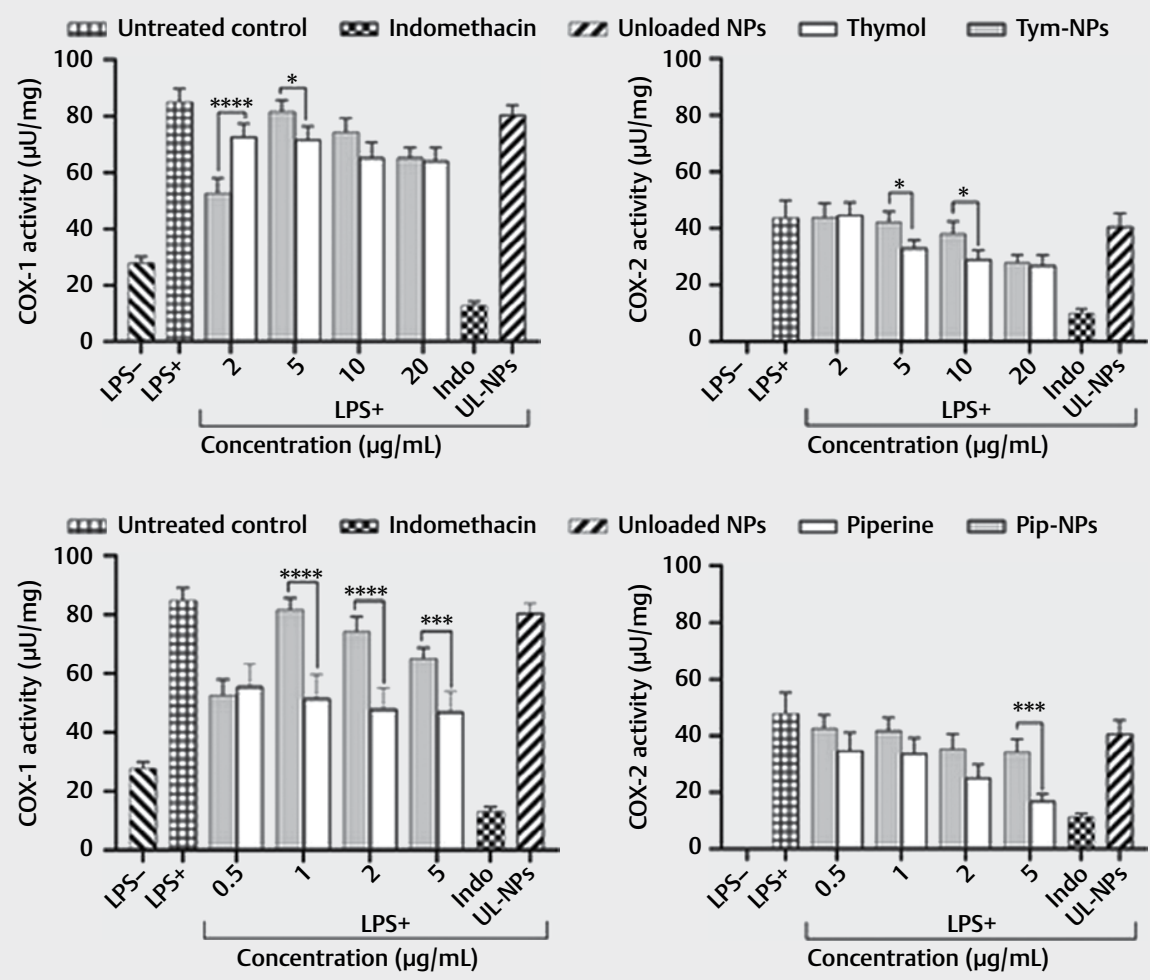

Fig. 6 Detection of COX-1 and COX-2 activity in LPS-stimulated Raw 264.7 cells lysate treated with free drugs or drug-loaded nanoparticles. Upper panel: thymol preparations; lower panel: piperine preparations. One unit $(\mathrm{U})$ of COX activity is the amount of enzyme that generates $1.0 \mu \mathrm{mol}$ of resorufin per minute at $\mathrm{pH} 8.0,25^{\circ} \mathrm{C}$. Indomethacin (Indo) was tested at $5 \mu \mathrm{g} / \mathrm{mL}$. Values are the mean of one experiment in triplicate $(n=3) \pm$ standard deviation. Statistical analysis was performed with Dunnett's multiple comparisons test using two-way ANOVA. ${ }^{*} P<0.05,{ }^{*}{ }^{*} p<0.01,{ }^{* *}{ }^{*} p<0.001$, and ${ }^{* * * *} p<0.0001$ between free drugs and drug-loaded nanoparticles.

chlorate (DiO), Griess reagent, and LPS from Escherichia coli 0111:B4 as well as dichloromethane were purchased from Sigma-Aldrich. Indomethacin (purity $\geq 98 \%$ ) was purchased from Sigma-Aldrich. Paclitaxel (purity $>97 \%$ ) was purchased from Cfm Oskar Tropitzsch. PLGA (Resomer RG 503 H, 50:50, Mw 24000-38000) was obtained from Boehringer Ingelheim Pharma GmbH\&Co. PVAL) (Mowiol 4-88, $31 \mathrm{kDa}$ ) was purchased from Clariant GMBH. WST-1 was obtained from Roche Diagnostics.

\section{Nanoparticle preparation}

The single emulsion solvent evaporation technique was used to encapsulate compounds with a drug to a polymer ratio of $1: 10$ (Text $1 \mathrm{~S}$, Supporting information).

\section{Characterization of poly(D,L-lactic-co-glycolic acid) nanoparticles}

Dynamic light scattering

The nanoparticles were suspended in milli-Q water, then the size and PDI were assessed by dynamic light scattering using a Malvern Zetasizer ZEN 3000 (Malvern Instruments, Ltd., U.K.). For zeta potential determinations, nanoparticles were dispersed in a $\mathrm{NaCl}$ $10 \mathrm{mM}$ solution prior to the measurement with a zetasizer (Malvern Zetasizer Nano series Nano-ZS).

\section{Scanning electron microscopy}

The nanoparticles morphology was determined using a scanning electron microscope (JSM-7001FA microscope; JEOL). A drop of nanoparticle suspension in milli-Q water was placed onto stubs and dried under vacuum. Then, they were coated with a 15-20 nm layer of gold and examined at $5.0 \mathrm{kV}$ emission.

\section{Entrapment efficiency and drug loading}

Lyophilized nanoparticles $(5 \mathrm{mg}$ ) were dissolved in dichloromethane and the optical density was measured using a UV-Vis absorbance reader (BioTek Instruments, SynergyMx, $\mathrm{GmbH}$ ) at 275, 280, and $341 \mathrm{~nm}$, respectively, for thymol, eugenol, and piperine. The amount of drug in the nanoparticles was then determined from a previously plotted calibration curve in dichloromethane. Drug loading (DL) and drug EE were calculated from equations ( 1 ) and (2), respectively:

(1) DL $(\%)=($ Amount of drug in nanoparticles/Amount of nanoparticles) $\times 100$

(2) $\mathrm{EE}(\%)=($ Amount of drug in nanoparticles/Initial amount of drug used) $\times 100$

\section{In vitro biological evaluation of nanoparticles}

Cell culture conditions and cell viability assay

The Raw 264.7 cells (ATCC) were cultured in DMEM culture media supplemented with $10 \%$ fetal calf serum and $1 \%$ antibiotics (100 
$\mathrm{IU} / \mathrm{mL}$ penicillin and $100 \mu \mathrm{L} / \mathrm{mL}$ streptomycin) and maintained at $37^{\circ} \mathrm{C}$ in a humidified atmosphere containing $5 \% \mathrm{CO}_{2}$. The WST- 1 assay was used to quantify cell viability as previously described [27].

Cellular uptake study

Raw 264.7 cells were seeded at $2 \times 10^{5}$ cells $/ \mathrm{mL}$ in $\mu$-slide 8 -well chamber slides (Ibidi $\mathrm{GmbH}$ ), and the experiment was performed in the dark (Text 2S, Supporting Information).

\section{Cell apoptosis analysis}

Raw 264.7 cells were seeded at $2 \times 10^{5}$ cells $/ \mathrm{mL}$ into 24 -well plates and incubated overnight, then treated with different concentrations of nanoparticles or free compounds. Paclitaxel $(0.5 \mu \mathrm{g} / \mathrm{mL})$ was included as a positive control. Untreated cells as well as cells exposed to unloaded nanoparticles were also included as controls. After $24 \mathrm{~h}$, cells were harvested and washed twice with warm PBS. The percentage of cells undergoing apoptosis was determined with an FITC Annexin V Apoptosis Detection Kit I (BD Biosciences) as per the manufacturer's instructions using a flow cytometer (BD LSR Fortessa cell analyzer). Data were analyzed with FCAP Array Software v3.0.

\section{Nitric oxide production assay}

The murine macrophage cells Raw 264.7 ( $2 \times 10^{5}$ cells/well in 96 well plates) were treated with different concentrations of nanoparticles or free compounds. After $24 \mathrm{~h}$, the organic nitrite concentration in the supernatant was measured as an indicator of NO production using the Griess reagent as previously described [28].

Cytokines measurement using cytometric bead array analysis activity

Raw 264.7 cells were seeded at $2 \times 10^{5}$ cells $/ \mathrm{mL}$ in 48 -well plates. After $24 \mathrm{~h}$, cells were treated with LPS $0.1 \mu \mathrm{g} / \mathrm{mL}$, then exposed to nanoparticles or free compounds. After $24 \mathrm{~h}$ of incubation, cell culture supernatants were collected and examined for IL-2, IL-4, IL-6, IL-10, IFN- $\gamma$, and TNF- $\alpha$ protein levels by multiplex cytokine array analysis performed using a BD Cytometric Bead Array Human Th1/ Th2 Cytokine Kit (BD-Biosciences). The assay was performed according to the manufacturer's instructions, and data were acquired on a BD LSR Fortessa cell analyzer flow cytometer. Indomethacin $(5 \mu \mathrm{g} / \mathrm{mL})$ was used as a positive control. Untreated cells as well as cells exposed to unloaded nanoparticles were also included.

\section{Cyclooxygenase- 1 and cyclooxygenase- 2 activity}

Raw cells were seeded at $2 \times 10^{5}$ cells $/ \mathrm{mL}$ in a 48 -well microplate, then treated with different concentrations of nanoparticles or free drugs, as well as LPS $0.1 \mathrm{\mu g} / \mathrm{mL}$. After $24 \mathrm{~h}$, COX-1 and COX-2 activity assays were performed (Text 3S, Supporting Information).

\section{Statistical analysis}

The data are presented as the mean \pm standard deviation (SD) of three independent experiments or triplicate $(n=3)$. Differences between means of each group were assessed by two-way ANOVA followed by Dunnett's multiple comparisons test using GraphPad Prism 8.

\section{Supporting Information}

The procedure for nanoparticle preparation, cellular uptake of nanoparticles by Raw 264.7 cells, the measurement of COX-1 and COX-2 activities, as well as the flow cytometry dot plots representing the apoptosis-inducing effect of nanoparticles and free drugs on Raw 264.7 cells are available as Supporting Information.

\section{Funding}

This work was supported by the Swiss National Foundation through the grant project $n^{\circ}$ IZSEZO_180383/1 and the Laboratory of Pharmaceutical Technology, Institute of Pharmaceutical Sciences of Western Switzerland, University of Geneva.

\section{Conflict of Interest}

The authors declare that they have no conflict of interest.

\section{References}

[1] Chen L, Deng H, Cui H, Fang J, Zuo Z, Deng J, Li Y, Wang X, Zhao L. Inflammatory responses and inflammation-associated diseases in organs. Oncotarget 2018; 9: 7204-7218

[2] Gkretsi V, Zacharia LC, Stylianopoulos T. Targeting Inflammation to Improve Tumor Drug Delivery. Trends Cancer 2017; 3: 621-630

[3] Karimi A, Majlesi M, Rafieian-Kopaei M. Herbal versus synthetic drugs; beliefs and facts. J Nephropharmacol 2015; 1: 27-30

[4] Karimpour M, Feizi MAH, Mahdavi M, Krammer B, Verwanger T, Najafi $F$, Babaei E. Development of curcumin-loaded gemini surfactant nanoparticles: Synthesis, characterization and evaluation of anticancer activity against human breast cancer cell lines. Phytomedicine 2019; 57: 183-190

[5] Jiang TA. Health Benefits of Culinary Herbs and Spices. J AOAC Int 2019; 102: 395-411

[6] Shityakov S, Bigdelian E, Hussein AA, Hussain MB, Tripathi YC, Khan MU, Shariati MA. Phytochemical and pharmacological attributes of piperine: A bioactive ingredient of black pepper. Eur J Med Chem 2019; 176: 149-161

[7] Derosa G, Maffioli P. Sahebkar A. Piperine and Its Role in Chronic Diseases. Adv Exp Med Biol 2016; 928: 173-184

[8] Barboza JN, da Silva Maia Bezerra Filho C, Silva RO, Medeiros JVR, de Sousa DP. An Overview on the Anti-inflammatory Potential and Antioxidant Profile of Eugenol. Oxid Med Cell Longev 2018; 2018: 3957262

[9] Meeran MFN, Goyal SN, Suchal K, Sharma C, Patil CR, Ojha SK. Pharmacological Properties, Molecular Mechanisms, and Pharmaceutical Development of Asiatic Acid: A Pentacyclic Triterpenoid of Therapeutic Promise. Front Pharmacol 2018; 9: 892

[10] Budama-Kilinc Y. Piperine Nanoparticles for Topical Application: Preparation, Characterization, In vitro and In silico Evaluation. ChemistrySelect 2019; 4: 11693-11700

[11] Zhao K, Li D, Shi C, Ma X, Rong G, Kang H, Wang X, Sun B. Biodegradable Polymeric Nanoparticles as the Delivery Carrier for Drug. Curr Drug Deliv 2016; 13: 494-499

[12] Pandey A, Jain DS. Poly lactic-co-glycolic acid (PLGA) copolymer and its pharmaceutical application. In: V K Thakur and M K Thakur, Eds. Handbook of Polymers for Pharmaceutical Technologies. Hoboken, New Jerseyand, Salem, Massachusetts, USA: John Wiley \& Sons, Inc. and Scrivener Publishing LLC; 2015: 151-172 
[13] Zhu Z, Min T, Zhang X, Wen Y. Microencapsulation of Thymol in Poly(lactide-co-glycolide) (PLGA): Physical and Antibacterial Properties. Mater 2019; 12: 1133

[14] Yag G, Calis S, Arica-Yegin B. The effect of inorganic salt type and concentration on hydrophilic drug loading into microspheres using the emulsion/solvent diffusion method. Drug Dev Ind Pharm 2014; 40: 390-397

[15] Jiang G, Thanoo BC, DeLuca PP. Effect of osmotic pressure in the solvent extraction phase on BSA release profile from PLGA microspheres. Pharm Dev Technol 2002; 7: 391-399

[16] Padhi S, Mirza MA, Verma D, Khuroo T, Panda AK, Talegaonkar S, Khar RK, Iqbal Z. Revisiting the nanoformulation design approach for effective delivery of topotecan in its stable form: An appraisal of its in vitro behavior and tumor amelioration potential. Drug Deliv 2016; 23: 2827-2837

[17] Bhatt $Y$, Shah D. Influence of additives on fabrication and release from protein loaded microparticles. Iran J Pharm Sci 2012; 8: 171-179

[18] Taciak B, Białasek M, Braniewska A, Sas Z, Sawicka P. Kiraga Ł, Rygiel T, Król M. Evaluation of phenotypic and functional stability of RAW 264.7 cell line through serial passages. PLoS One 2018; 13: e0198943

[19] Xiong S, Zhao X, Heng BC, Ng KW, Loo JS. Cellular uptake of Poly-(D,L-lactide-co-glycolide) (PLGA) nanoparticles synthesized through solvent emulsion evaporation and nanoprecipitation method. Biotechnol J 2011; 6: 501-508

[20] de Castro CE, Ribeiro CAS, Alavarse AC, Albuquerque LJC, da Silva MCC, Jäger E, Surman F, Schmidt V, Giacomelli C, Giacomelli FC. Nanoparticle-Cell Interactions: Surface Chemistry Effects on the Cellular Uptake of Biocompatible Block Copolymer Assemblies. Langmuir 2018; 34: 2180-2188
[21] Boscá L, Hortelano S. Mechanisms of nitric oxide-dependent apoptosis: Involvement of mitochondrial mediators. Cell Signal 1999; 11: 239-244

[22] Martin KR, Ohayon D, Witko-Sarsat V. Promoting apoptosis of neutrophils and phagocytosis by macrophages: novel strategies in the resolution of inflammation. Swiss Med Wkly 2015; 145: w14056

[23] Manayi A, Nabavi SM, Setzer WN, Jafari S. Piperine as a Potential Anti-cancer Agent: A Review on Preclinical Studies. Curr Med Chem 2018; 25: 4918-4928

[24] Jamali T, Kavoosi G, Safavi M, Ardestani SK. In-vitro evaluation of apoptotic effect of OEO and thymol in 2D and $3 \mathrm{D}$ cell cultures and the study of their interaction mode with DNA. Sci Rep 2018; 8: 15787

[25] Su H, Lei CT, Zhang C. Interleukin-6 Signaling Pathway and Its Role in Kidney Disease: An Update. Front Immunol 2017; 8: 405

[26] Lee M, Rey K, Besler K, Wang C, Choy J. Immunobiology of Nitric Oxide and Regulation of Inducible Nitric Oxide Synthase. Results Probl Cell Differ 2017; 62: 181-207

[27] Leutcha BP, Sema DK, Dzoyem JP, Ayimele GA, Nyongbela KD, Delie F, Alléman É, Sewald N, Meli Lannang A. Cytotoxicity of a new tirucallane derivative isolated from Stereospermum acuminatissimum K. Schum stem bark. Nat Prod Res 2020: 1-6

[28] Dzoyem JP, Donfack ARN, Tane P, McGaw L], Eloff JN. Inhibition of nitric oxide production in LPS-stimulated RAW264.7 macrophages and 15-LOX activity by anthraquinones from Pentas schimperi. Planta Med 2016; 82: 1246-1251 